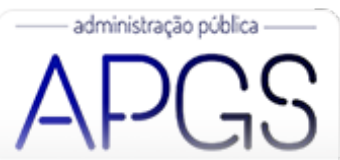

Administração Pública e Gestão Social ISSN: 2175-5787

apgs@ufv.br

Universidade Federal de Viçosa

Brasil

\title{
"E Agora, José?" Decisões Coletivas e Relações Familiares em Finanças Solidárias
}

Romero Tavares do Nascimento, Ives; Scalfoni Rigo, Ariádne

"E Agora, José?" Decisões Coletivas e Relações Familiares em Finanças Solidárias

Administração Pública e Gestão Social, vol. 12, núm. 2, 2020

Universidade Federal de Viçosa, Brasil

Disponible en: http://www.redalyc.org/articulo.oa?id=351562414001

Esta obra está bajo una Licencia Creative Commons Atribución-NoComercial-SinDerivar 3.0 Internacional. 


\section{“E Agora, José?” Decisões Coletivas e Relações Familiares em Finanças Solidárias}

"Then What, José?" Collective Decisions and Family Relations in Solidarity Finance
"¿Y ahora, José?" Decisiones Colectivas y Relaciones Familiares en Finanzas Solidarias

Ives Romero Tavares do Nascimento

Universidade Federal do Cariri, Brasil

Redalyc: http://www.redalyc.org/articulo.oa?

ives.tavares@ufca.edu.br

Ariádne Scalfoni Rigo

Universidade Federal da Bahia, Brasil

ariadnescalfoni@gmail.com

id $=351562414001$

Recepción: 06 Junio 2017

Aprobación: 16 Marzo 2018

Publicación: 01 Abril 2020

\section{Aspectos teóricos do caso: As finanÇas Solidárias e os Bancos Comunitários de DesenVolvimento (BCDs)}

Compreender o universo das finanças solidárias e dos Bancos Comunitários de Desenvolvimento (BCDs) demanda a tarefa primeira de se tratar dos conceitos de microcrédito, microfinanças e finanças solidárias e como estas se atrelam aos próprios BCDs.

Para entender o que são as microfinanças, cumpre retomar a ideia de finanças. Por este conceito, de um modo geral, englobam-se todas as operações e movimentações de dinheiro, envolvendo a circulação de moeda, oferta e demanda de crédito dentro e fora de relações bancárias. Se as finanças podem ser conceituadas dentro de um escopo maior, as microfinanças se caracterizam como as finanças feitas em menor escala, que envolvem menores valores (França Filho et al., 2012).

As microfinanças, por sua vez, geralmente são uma das composições de serviços financeiros ofertados a comunidades mais empobrecidas, que comumente possuem menor capacidade de consumo e endividamento ocasionada pela baixa possibilidade de oferta de garantias reais. Dentro das microfinanças existe a figura do microcrédito, que usualmente é destinado ao financiamento de atividades produtivas realizadas por aqueles postos à margem da concessão tradicional de empréstimos. Nesses casos, a garantia para o crédito não é embasada na existência de garantias reais do tomador do empréstimo, mas sim pela garantia solidária do solicitante.

Em outros termos, isso quer dizer que a concessão do recurso financeiro se dá mediante relações de proximidade que o tomador tem em sua comunidade - afeto, boa índole e reputação favorável, por exemplo - e que servem como a garantia do pagamento do valor emprestado. O interessante é que esta metodologia desponta como uma alternativa de inclusão econômica e social quando se objetiva proporcionar o acesso a recursos financeiros a integrantes de sociedades em condições de exclusão financeira ou de acesso precário ao sistema financeiro tradicional (bancos e operadores).

Todavia, como imaginar a operacionalização de microcréditos por instituições que exigem uma garantia em troca da concessão de crédito, como o sistema bancário tradicional? França Filho (2013) aponta que uma das organizações que fogem dessa realidade é o Banco Comunitário de Desenvolvimento (BCD), empreendimento de economia solidária que tem como uma das principais funções a viabilização do empréstimo de dinheiro com base nas relações de proximidade entre os indivíduos. Diferentemente de um banco tradicional, os BCDs contam com agentes de crédito que, ao receberem uma solicitação de 
empréstimo, saem pela comunidade em busca de conhecer mais sobre a reputação do tomador (quando não o conhecem de antemão) e se reúnem sob o Conselho de Avaliação de Crédito (CAC), órgão deliberativo do $\mathrm{BCD}$, onde discutem sobre a viabilidade ou não da concessão do recurso requerido.

Autores nacionais de economia solidária (Rigo, 2014; Leal, 2013; França Filho, 2013) afirmam que uma das características mais peculiares dos BCDs é a viabilização do empréstimo por meio de moedas sociais, paralelas à oficial do país, devidamente lastreadas, que restringem as trocas mercantis - compra e venda - à zona de atuação do BCD que as emitiu. Dessa maneira, os recursos financeiros disponibilizados pelo BCD circulam pelo território do tomador de empréstimo, evitando que as riquezas locais sejam evadidas para outros espaços. Com isso, estimula-se o desenvolvimento de diferentes ações de negócio que já existem na localidade (mercadinhos, quitandas, etc.) e fomentam o surgimento de outras novas (depósitos de material de construção e revenda de gás de cozinha, por exemplo). Cumpre dizer que a instituição de uma moeda social para um determinado grupo social é concomitante ao surgimento do próprio BCD que a emite.

Figura 01: Moeda Social Maracanã, do Banco Paju, Maracanaú (CE)

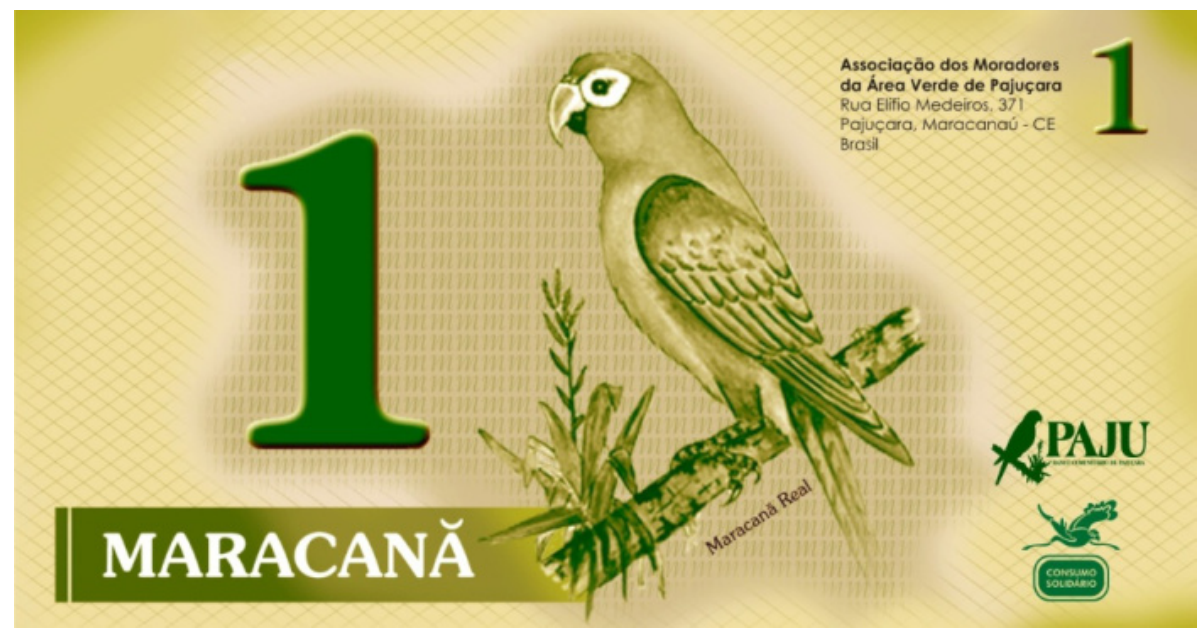

FIGURA 01

Moeda Social Maracanã do Banco Paju Maracanaú CE

Nota. Fonte: Costa, 2013.

Quando um banco comunitário é criado, sua fase de planejamento e organização envolve um acordo formal com os donos dos estabelecimentos comerciais locais para que estes aceitem, junto com o Real, a moeda social que o BCD colocará em circulação quando do seu funcionamento. Isso garantirá que qualquer tomador de empréstimo, munido de moedas sociais, possa adquirir um bem ou um serviço com elas. O comerciante, então, terá três opções: a) Dirige-se ao banco comunitário para fazer a troca por Reais; b) utiliza as moedas sociais como troco em outras operações de compra e venda; c) faz o pagamento dos seus fornecedores com as moedas sociais. Ao retornar ao $\mathrm{BCD}$, a moeda poderá ser emprestada novamente. O importante é que a riqueza seja constantemente mantida dentro da comunidade por meio da impossibilidade de as moedas sociais não serem aceitas fora dali. A Figura 02 abaixo apresenta a esquematização do circuito básico das moedas sociais em um território: 


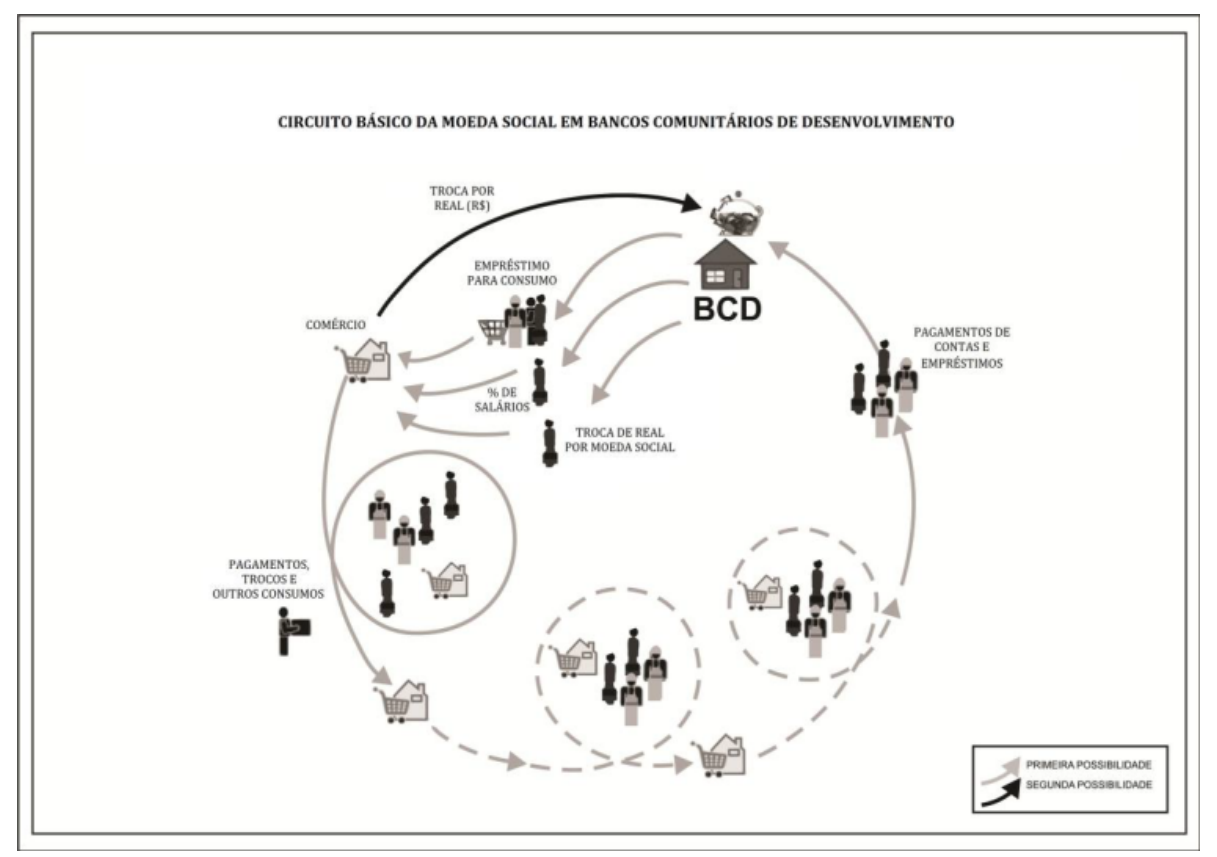

FIGURA 02

Representação do circuito básico da moeda social nos BCDs Nota. Fonte: Rigo, 2014, (re)elaborado a partir de França Filho, Rigo e Leal (2011).

No Brasil, a experiência pioneira dos BCDs está localizada na periferia de Fortaleza (CE), o Conjunto Palmeiras, onde o Banco Palmas desde 1998 atua no desenvolvimento local por meio da concessão de empréstimos em Palmas, a moeda social do banco, e em Real por meio de diversas linhas de crédito, como Consumo e Produção.

É nesse cenário, então, que as finanças solidárias se constituem: Atuando onde as finanças tradicionais não conseguem agir, baseiam-se na ética e na proximidade para oportunizar o acesso ao crédito e, consequentemente, ao trabalho e à renda, na busca pela democratização dos recursos financeiros. Com isso, espera-se evitar que apenas as pessoas mais ricas sejam detentoras de empreendimentos e pequenos negócios (Muñoz, 2009). Por todo o território brasileiro são identificadas experiências exitosas de microfinanças, sob diversos formatos (bancos comunitários, fundos rotativos solidários, cooperativas de crédito, dentre outras), e por essa razão esses empreendimentos têm-se espalhado por todo o país. No ano de 2013, por exemplo, já eram mais de 100 bancos comunitários ativos em todo o país com moedas sociais próprias, que recebem diariamente diferentes solicitações de crédito para consumo, produção e (ou) obras de infraestrutura.

Todavia, nem sempre as demandas de crédito nos BCDs são facilmente atendidas. Os motivos são muito diversos. Alguns pedidos se mostram de difícil decisão para os membros dos comitês de avaliação de crédito (CACs), posto que a concessão ou não do empréstimo reflete diretamente em consequências para o banco e para a comunidade, como a imagem da instituição, sua confiança perante a comunidade e impossibilidade de reposição do fundo de crédito do BCD. Diariamente os membros dos CACs são levados a ponderar sobre questões que transpassam a relação econômica entre as pessoas e se inserem na seara das relações familiares e de proximidade entre os indivíduos. É o que será visto no caso relatado a seguir.

\section{Contextualização do caso [I]}

Manguinhos é uma comunidade com pouco mais de 700 famílias localizada no litoral nordestino, onde sua população vive basicamente de atividades ligadas ao mar, como a pesca e a mariscagem. Há uma divisão do trabalho fortemente baseada em questões de gênero: Os homens se dedicam à piscicultura e à pesca e as 
mulheres, à tessitura de peças de renda e mariscagem. Todavia, a renda per capita local não ultrapassa os R\$ 200,00 , o que obriga a maioria dos moradores a buscar fontes complementares de renda. Como pouco mais de $15 \%$ dos habitantes dedica-se às atividades marítimas, a comunidade precisou de uma alternativa de acesso à renda.

No ano de 2007, juntamente com uma empresa privada e uma instituição de ensino superior, a comunidade cria um banco comunitário, chamado aqui de BCD Rio do Mar, na perspectiva de ter um empreendimento capaz de ofertar microcréditos baseados nas relações de proximidade locais que pudessem suprir a demanda por empréstimos para produção e consumo, visto que a maioria dos moradores de Manguinhos não poderia conseguir recursos financeiros em um banco comercial tradicional. Anos mais tarde, o Rio do Mar consegue manter-se ainda ativo mesmo com frequentes inadimplementos dos seus devedores, o que prejudica em parte o fundo de crédito do BCD. Mas seu presidente, o "Seu" José, é uma liderança local que consegue, por meio das relações de amizade e confiança que estabeleceu com os vizinhos, pagamentos para sustentar um nível mínimo de Reais para lastrear a moeda social que ali circula mensalmente.

Ao chegar em casa depois de mais um dia dirigindo o BCD, "Seu" José comenta com a esposa que o banco comunitário está atravessando dificuldades financeiras e o fundo de crédito já não suporta mais tantos atrasos nos pagamentos dos devedores, completando que o CAC, a partir do dia seguinte, seria mais rigoroso com as solicitações de novos empréstimos e de renovações. Nesse cenário, incluem-se outros agravantes. Em primeiro lugar, existe uma alta taxa de inadimplência dos tomadores de empréstimos, muito comum no ambiente dos bancos comunitários. Para além da impossibilidade financeira de adimplemento (falta de dinheiro para quitar a dívida com o $\mathrm{BCD}$ ), há a crença popular de que o crédito não precisa ser devolvido ou é a "fundo perdido", uma vez ser oriundo de uma doação de governos e empresas privadas, que não exigem um bem como garantia do não-pagamento. Soma-se a baixa ou ausente capacidade gerencial dos tomadores de crédito, que leva à inviabilidade dos seus empreendimentos e à consequente inadimplência.

"Apesar de todos os problemas", pensa ele, "nossa comunidade mudou para melhor depois que o banco passou a atuar. Não podemos deixá-lo nessa situação!”. É nesse momento que o dirigente do banco rememora os primeiros anos. Naquela ocasião os membros da comunidade estavam motivados para alcançar conquistas e melhorias sociais (educação, saúde e emprego e renda, por exemplo) e, cansados de pleitear junto à Prefeitura Municipal a mudança esperada, os moradores entram em contato com uma empresa privada com atuação local para encontar uma solução para esses problemas.

A saída encontrada pela iniciativa privada foi firmar um convênio com uma universidade próxima que, por meio de uma incubadora universitária de economia solidária, propôs a criação de uma Rede Local de Economia Solidária como alternativa. De posse do aceite da empresa e da comunidade, uma das primeiras ações da incubadora foi a reativação da associação comunitária, seguida por um mapeamento das potencialidades sociais, econômicas, culturais e históricas de Manguinhos, com o intuito de enxergar quais possíveis empreendimentos - e, consequentemente, novos postos de trabalho - poderiam ser criados.

A criação do BCD Rio do Mar, segundo a incubadora, era essencial para o financiamento de todas as atividades da rede que ali estava sendo tecida, tanto para os empreendimentos quanto para os consumidores locais. Assim, a empresa doa um montante para o fundo do crédito do banco que logo o disponibiliza em Reais e em Escamas, a moeda social criada pela comunidade para si.

É então que "Seu" José se dá conta de que muitos empreendimentos foram viabilizados (10 iniciativas apoiadas), como o grupo de ostreicultura e diversos empréstimos para consumo liberados (aproximadamente 30 empréstimos), atendendo ao anseio daqueles em situação de extremo risco econômico para a aquisição de alimentos (em média, o BCD vinha recebendo cinco solicitações de crédito para consumo por dia). Assim, os recursos do fundo de crédito estavam cada vez mais escassos, tendo em vista o baixo retorno. Mais uma vez “Seu” José diz para si mesmo: “O banco não pode deixar de existir!”, mas, ao se preparar para dormir, ele não imagina que outra família teria, nos próximos meses, a vida entrelaçada com o BCD Rio do Mar. 
Perto dali vive Antônio Silva, pescador de 27 anos que mora com sua esposa Ana Maria e se sente muito satisfeito com seus ganhos, os quais, complementados com a renda de sua mulher, que trabalha com bordados, garantem ao casal uma vida tranquila. Contudo, o sogro de Antônio, "Seu” Jair, que também sobrevive da pesca em Manguinhos, adoece e, como mora sozinho, passa a necessitar que sua filha, juntamente com o marido, se mude para sua casa no intuito de ajudá-lo com as tarefas domésticas e auxiliá-lo com o tratamento médico.

\section{A mudança na VIDA de Antônio e Ana Maria}

Diante da nova realidade e necessidade urgente do sogro, Antônio toma uma decisão:

- Ana Maria, - fala Antônio para sua esposa - não podemos deixar seu pai sozinho e vamos morar com ele, mas me pergunto como ficará nossa vida se sairmos daqui. Já moramos aqui na vila há algum tempo e fico preocupado se na comunidade do "Seu" Jair também conseguiremos sobreviver.

- Querido, não pense assim. - retruca a mulher - Acharemos uma saída. O que não posso é ficar aqui e ver meu pai precisar de nossa ajuda e negá-la. Vamos, dará tudo certo!

Assim, Antônio se muda com sua esposa para a casa do sogro, e seus problemas financeiros logo começam. Primeiro porque Ana Maria deixou de bordar por causa dos afazeres que passou a ter e, em segundo, porque o próprio Antônio teve que se ambientar em um novo espaço para começar a trabalhar.

Vendo a situação ficar preocupante, Antônio começa a procurar uma forma de reverter esse dilema. "Vou voltar a pescar amanhã mesmo", pensou ele. Todavia, percebe que necessita de novos equipamentos, tendo em vista que os seus já se encontram bastante gastos. Novamente se indaga: "Então, como vou conseguir esse dinheiro? Meu sogro não está bem e eu não possuo bens ou renda para ir a um banco. E agora?”

Ao saber da dificuldade do genro, "Seu" Jair menciona a existência de um Banco Comunitário de Desenvolvimento (BCD) na comunidade onde vivem e fala que a lógica de empréstimos é diferente. Ele mesmo era um frequente tomador de créditos. No BCD Rio do Mar, os recursos são concedidos com base na solidariedade e na confiança existente nas relações dos moradores da comunidade, sem a existência de bens ou renda em garantia.

"Esta é a solução para meus problemas!", exclamou Antônio imediatamente para seu sogro. "Amanhã mesmo vou até o banco pedir um empréstimo desses". Orientado por "Seu” Jair, Antônio fez um orçamento do que precisava comprar num comércio da vizinhança e se dirige ao BCD munido do documento. Ao chegar lá, conversou com Valdo, agente de crédito que estava no local. Durante a conversa, ele revela a existência de uma linha de crédito específica para a produção de bens e serviços e que levaria sua demanda ao Comitê de Avaliação de Crédito (CAC) do banco na próxima reunião agendada. Tendo solicitado R \$500,00 para iniciar uma venda de lanches rápidos em casa, Antônio acredita que sua ideia de negócio vai prosperar. Ainda que fosse um valor superior à renda média das pessoas que ali vivem ( $\mathrm{R} \$ 200,00)$, tudo parecia ser favorável aos seus planos.

\section{O BCD se PRonunCia: "E agora, José?"}

Com o encontro presidido por José, o CAC delibera sobre as solicitações feitas durante os últimos dias e se depara com o caso de Antônio, procedendo à análise do pedido. Ao averiguar-se que o solicitante tinha todos os requisitos para que seu crédito fosse aprovado, "Dona" Mariinha, um dos membros do CAC, lembrouse de que Antônio era genro do "Seu" Jair, e este não tinha pago o último empréstimo feito também para produção, que era destinado à compra de uma canoa. 
- Dessa forma, não podemos conceder o crédito, como está escrito nas normas do banco -, falou Dona Mariinha. - Não podemos conceder um novo empréstimo para uma mesma residência quando houver pelo menos um integrante da mesma família com débito no Rio do Mar.

É quando Valdo intervém:

- Todavia, "Seu" Jair sempre foi um ótimo pagador dos empréstimos feitos junto ao banco e tem uma conduta muito correta na comunidade. Sabemos que o crédito não será utilizado por ele, mas sim por seu genro, o Antônio. Temos que nos lembrar da função social do Rio do Mar e conceder o crédito.

Diante desta perspectiva, alguns membros levantaram a possibilidade de conceder o crédito mesmo com a norma proibitiva, no intuito de oportunizar o acesso à renda para um morador da comunidade que efetivamente precisa do recurso. Mas "Dona" Mariinha retruca:

- Mas ele ainda não reside há mais de seis meses aqui, outra norma do banco. Conceder o empréstimo ferindo duas normas já estabelecidas e conhecidas por todos pode ser ruim para a imagem do banco, que está com o fundo de crédito bastante debilitado. Isso pode acarretar sérias consequências para a imagem de nossa instituição e também para o fundo de crédito, que já não está tão amplo assim... Antônio solicitou 500 Reais, o que é razoável para o início de um pequeno negócio, mas é um valor superior ao que o Banco tem concedido ultimamente para os outros usuários. Se esse valor não for pago, teremos problemas para conceder novos empréstimos.

Em meio a este embate de argumentos pró e contra a liberação do valor solicitado por Antônio, o CAC se depara com uma situação delicada: Se decide pela não concessão do crédito, protege o fundo do banco e ajudará a mantê-lo por mais tempo, além de não abrir precedentes para que outros burlem as já consolidadas regras do Rio do Mar. Além disso, conceder o empréstimo para Antônio poderia causar na comunidade a sensação de que a partir de então poderiam ser emprestados recursos para uma residência onde há um inadimplente, podendo causar desconfiança entre os usuários. Mas, por outro lado, impedirá que um morador - ainda que recentemente ali integrado - seja beneficiado pelo objetivo maior do BCD que é a inclusão social (por meio do acesso facilitado ao microcrédito).

O CAC pressiona por uma decisão do grupo e, sem saber qual posicionamento adotar por causa da singularidade e da complexidade da situação, se pergunta: "E agora, José?".

\section{NotAS DE ENSINO}

As notas de ensino aqui dispostas são compostas por um conjunto de ferramentas que o professor poderá utilizar em momentos e espaços de formação no nível da graduação, da pós-graduação, cursos de extensão, treinamento e aperfeiçoamento.

\subsection{Objetivos educacionais}

Este caso de ensino foi elaborado com o objetivo de ser utilizado em disciplinas de Gestão Social e (ou) Economia Solidária, bem como aquelas que possuam em suas ementas tais assuntos. É, ainda, recomendado para formações de diferentes níveis que tratem de organização comunitária, incubação de empreendimentos de economia solidária, microfinanças, microcrédito, finanças solidárias e moedas sociais. Todavia, é preciso salientar que este Caso Para Ensino deve ser utilizado em turmas que já tenham um contato prévio com as temáticas da economia solidária e das microfinanças, uma vez que os princípios dessas duas temáticas devem ser conhecidos para que este Caso seja bem compreendido e analisado.

Cursos com o viés interdisciplinar em sua estrutura curricular poderão utilizá-lo em contextos transversais ao tratar de políticas públicas para o desenvolvimento local e territorial, desde que contextualizado. 


\subsection{Questões para discussão}

Durante a abordagem do caso, estas e outras questões podem ser trabalhadas pelo docente:

a) Qual o principal dilema apresentado no caso? Por que ele se mostrou tão delicado para o CAC resolver?

b) Quais as implicações de cada uma das decisões enxergadas pelo Comitê? Em outros termos, quais as vantagens e desvantagens de cada medida considerada pelo Banco? De que maneira a temática da resolução de conflitos seria útil nessa situação?

c) Como evitar que o fundo de crédito do banco fique tão baixo? Como prever estas situações que extrapolam as regras de concessão do crédito, mas que são importantes para os moradores da comunidade?

d) A Gestão Social e a Economia Solidária podem ser utilizadas como fontes de princípios na resolução das questões acima mencionadas? Se sim, de que forma?

\subsection{Aspectos pedagógicos}

O intuito deste caso é fomentar o debate em sala de aula sobre as experiências reais de Bancos Comunitários de Desenvolvimento brasileiros, visto que esta ferramenta educacional complementa a teoria abordada pelo professor/formador. Neste caso de ensino, poderá ser utilizado o recurso das artes cênicas em atos teatrais de curta duração (esquetes) onde os alunos protagonizem a narração e a discussão do CAC aqui retratada. O que se intenciona com estas metodologias adicionais é a interação entre os alunos e sua visualização do cotidiano de um banco comunitário, principalmente da complexidade das decisões que diariamente nele são tomadas.

\subsection{Alternativas para a solução do caso}

Com base nas diversas possibilidades apontadas na descrição do caso, o CAC do banco decidiu então não autorizar o empréstimo, priorizando o atendimento às regras de concessão dos créditos. O interesse coletivo se sobrepôs ao individual.

Todavia, apontamos questões alternativas para a solução do caso, as quais o professor poderá debater com seus alunos, além de propor outras novas:

a) O crédito poderia ser concedido integralmente, mesmo sem observar os dispositivos legais do BCD apontados por "Dona” Mariinha, admitindo excepcionalmente o caráter de urgência do solicitante e de utilidade social que os bancos comunitários devem possuir. Como medida imediata, a decisão poderia ser sucedida por uma revisão das normas e inseridas as exceções que abrandassem a concessão de crédito quando o CAC se deparasse com emergências. Além disso, após a concessão, poderiam ser revistos o sistema de definição de regras, monitoramento e penalidades em organizações de ação coletiva;

b) O crédito também poderia ser aprovado parcialmente, com a liberação das parcelas restantes mediante a adimplência do "Seu" Jair (que também teria sua dívida renegociada). Por exemplo: Considerando o valor solicitado de $\mathrm{R} \$ 500,00$, o CAC poderia autorizar a liberação de $\mathrm{R} \$ 250,00 \mathrm{em}$ uma primeira saída e os $\mathrm{R} \$ 250,00$ restantes só seriam concedidos quando o débito da residência fosse quitado. Isso resolveria momentaneamente a urgência do solicitante, forçaria o cumprimento da obrigação de seu sogro e a imagem do banco comunitário não seria profundamente afetada;

c) De modo transversal às soluções aqui propostas e que está implícita no Caso, apontamos uma das principais dificuldades que os BCDs enfrentam cotidianamente: As altas taxas de inadimplência. Devido à natureza de formação dos fundos de crédito de muitos bancos comunitários ser os Termos de Ajuste de Conduta (TAC) de empresas públicas e privadas, muitos usuários desenvolvem a crença de que o recurso não precisa ser devolvido, visto que já é de propriedade de todos, o que provoca o esvaziamento do fundo passível de empréstimo e o descrédito da instituição perante a comunidade. Outro motivo é a "morte" prematura 
de muitos micro e pequenos empreendimentos de economia solidária, iniciados em muitos casos a partir de empréstimos voltados à produção local. Seus dirigentes, em grande parte, não possuem preparo para atuação no mercado e não conseguem gerir seus negócios de modo a promover sua sustentabilidade. Sem capital, muitos empreendedores não conseguem quitar seus débitos com os BCDs;

d) Outra alternativa complementar e imediata é o estímulo ao consumo interno em moeda social através de descontos feitos com ela nos empreendimentos que a aceitem, que também poderia ser dado pelo BCD quando o comerciante trocasse suas moedas sociais. Sorteios de produtos e brindes e realização de feiras solidárias aparecem como complementação. Para o médio e longo prazo, formações, palestras e reuniões com a comunidade sobre as vantagens das moedas sociais e dos bancos comunitários para o desenvolvimento local podem ser estratégias eficientes. Ainda que se refira diretamente à gestão do $\mathrm{BCD}$ e do fundo de crédito, mantém relação direta com a existência de uma maior margem de empréstimo, o que facilitaria a decisão a ser tomada;

e) Por fim, as temáticas do cooperativismo, do associativismo, das finanças solidárias e afins podem ser inseridas nos debates estimulados nos Aspectos Pedagógicos.

\subsection{Sugestôes de assuntos a serem trabalhados}

De ordem mais geral: Relações comunitárias e sua influência nas finanças solidárias e de proximidade, relações pessoais nas estruturas de gestão coletivas, diferenças entre microcrédito e finanças solidárias.

De modo mais específico: O papel dos CACs nos BCDs, o papel dos CACs enquanto espaços responsabilização da comunidade pelas decisões tomadas, os prós e contras das influências das relações familiares na dinâmica dos BCDs.

\section{REFERENCIAS}

França Filho, G. C. de. (2013). Bancos Comunitários de Desenvolvimento (BCD's) como expressão de Finanças Solidárias: por uma outra abordagem da inclusão financeira. 1. ed. Fortaleza - Ceará: Arte Visual.

França Filho, G. C. de., Silva Júnior, J. T., \& Rigo, A. S. (2012). Solidarity finance through community development banks as a strategy for reshaping local economies: lessons from Banco Palmas. Revista de Administração (FEAUSP), 47. 500-5015. Recuperado de: http://www.rausp.usp.br/download.asp?file=v473500.pdf.

Costa, F. N. Moedas Sociais, Complementares ou Locais. Cidadania \& Cultura, 2013. Recuperado de: https://fernand onogueiracosta.wordpress.com/2013/08/05/moedas-sociais-ou-locais/.

Leal, L. P. (2013). Gestão Coletiva dos Bens Comuns na Experiência dos Bancos Comunitários de Desenvolvimento: $o$ Caso de Matarandiba. Dissertação de Mestrado. Núcleo de Pós-Graduação em Administração da Escola de Administração da Universidade Federal da Bahia (NPGA/EA/UFBA).

Muñoz, Ruth. (2009). Finanças solidárias. In: A. D. Cattani et al. (eds.) Dicionário internacional da outra economia (pp. 208-213) Porto Alegre: Edições Almedina.

Rigo, A. S. (2014). Moedas Sociaise Gestão de Territórios: Aplicações e Implicações Teóricas e Práticas. Tese de doutorado. Núcleo de Pós-Graduação em Administração da Escola de Administração da Universidade Federal da Bahia (NPGA/EA/UFBA).

\section{Notas}

[i] O caso aqui apresentado é verídico e aconteceu em uma experiência de um Conselho de Avaliação de Crédito (CAC) de Banco Comunitário de Desenvolvimento baiano, mas os nomes da localidade, do BCD e dos envolvidos foram trocados para preservar a identidade dos mesmos. 
Administração Pública e Gestão Social, 2020, 12(2), AbriL-Julio, ISSN: 2175-5787

CC BY-NC-ND 